\title{
Francis Ponge e as razões da poesia
}

Danielle Grace de Almeida

UFRJ

\begin{abstract}
Resumo
Este artigo tem por objetivo discutir a relação entre a poesia de Francis Ponge e a escrita como espaço de intervenção social. Ao examinar a criação poética na modernidade, passando pela encenação da figura do poeta desde o romantismo, seria possível dizer que o papel do escritor modifica-se no tempo-espaço em que se inscreve, sem, no entanto, deixar de imprimir seu impacto sobre a realidade político-social. Nesse sentido, pretende-se colocar em diálogo o texto "Raisons d'écrire", escrito crítico-poético em que Ponge fala da sua relação com a escrita e com o mundo, e certas considerações teóricas que, a exemplo de Jacques Rancière, em Politicas da escrita, nos permitem refletir sobre o papel da escrita no rearranjo do que se torna passível de ser pensado, dito e realizado no cerne de uma sociedade.
\end{abstract}

Palavras-chave: Francis Ponge; Modernidade; Poesia; Política.

\section{Résumé}

Cet article a pour but de discuter le rapport entre la poésie de Francis Ponge et l'écriture en tant qu'espace d'intervention sociale. En examinant la création poétique dans la modernité, et étant donné la mise en scène de la figure du poète dès l'époque romantique, il serait possible d'affirmer que le rôle de l'écrivain se modifie-t-il dans l'espace-temps où il s'inscrit, sans, pourtant, laisser d'empreindre la réalité politique-sociale de son impact. En somme, il s'agit de faire dialoguer "Raisons d'écrire », texte critique-poétique où Ponge parle de sa relation avec l'écriture et le monde, et certaines considérations théoriques qu'à exemple de ce que nous dit Jacques Rancière dans Políticas da escrita nous permettent de réfléchir sur le rôle de l'écriture dans l'arrangement de ce qui devient possible d'être pensé, dit, vu et fait au sein d'une société.

Mots-clés: Francis Ponge; Modernité, Poésie; Politique. 
1. MALLARMÉ, Stéphane. Cuvres Complètes II, 2003, p. 205.

2. Ibidem, p. 206.

3. MAULPOIX, Jean-Michel. Du Lyrisme, 2000, p. 417.

Todas as traduções dos textos estrangeiros citados neste artigo são de minha autoria.
Desde Baudelaire, a poesia teve que se haver com novas problemáticas. A começar por um mundo em transformações físicas e morais que, nesse sentido, deixa necessariamente um legado linguístico e artístico. Apesar de essa constatação ser um terreno visitado pela crítica, é preciso repensar esse percurso na perspectiva de uma crise que não abala somente as regras tradicionais que regiam a poesia, pois ela coloca em questão também o próprio lugar do poeta nessa relação complexa entre escrita e responsabilidade social. Dizendo de outra maneira, a crise da modernidade parece ser além de tudo um fator de reajuste do entrelaçamento entre um ideal moral - produzido pelo autor e visando a interferir na realidade cotidiana - e a prática literária. Sendo assim, podemos afirmar que a revolução literária nesse momento, mesmo apontando para um questionamento que se quer estético, não deixa de reivindicar a crise que diz respeito ao valor da poesia em um mundo de transformações sociais.

A “crise de vers" anunciada por Mallarmé é sobretudo a comprovação de que a literatura passa por um momento de reconfiguração de seu papel: "La littérature ici subit une exquise crise, fondamentale"1. O texto, que é um marco justamente por explicitar essa tensão entre o escritor, a sua posição no mundo e a relação com o próprio fazer literário, traz uma menção clara ao lugar da poesia e do poeta nessa crise da "literatura". Nota-se isso primeiramente pela presença da palavra 'verso', já no título, depois pelas referências ao estado de luto do leitor francês pela morte recente do poeta Victor Hugo, que Mallarmé caracteriza como "le vers personnellement": "Un lecteur français, ses habitudes interrompues à la mort de Victor Hugo, ne peut que se déconcerter".

As formulações de Mallarmé servem para anunciar uma arte poética que se realiza através da explosão das regras formais de versos e rimas consagradas pela tradição. Nesse momento, a poesia se volta para a materialidade da língua. Com Mallarmé, o sentido de um poema encontra-se na problematização da forma e do conteúdo, nos "entres" das palavras, nos brancos da página, nos vazios, no silêncio, nos nadas. Nessa perspectiva, Maulpoix, em Du Lyrisme, lembra que

\footnotetext{
desde Mallarmé, o silêncio define as condições da escrita poética. Era preciso de fato que se tocasse no verso, que se escrutasse $\mathrm{o}$ ato de escrever até sua origem, e que se fizesse desaparecer elocutoriamente o poeta para que o silêncio se tornasse um elemento inteiramente da poesia, e como seu princípio. ${ }^{3}$
}

Nesse momento da poesia francesa, essa mudez explode os limites puramente sentimentais e físicos do autor para, com Mallarmé, fazer-se presente na língua, "escrutando", como afirmou Maulpoix, o "ato de escrever até a sua origem". Não se 
trata, então, de resistir à escrita, mas de expor os ruídos da expressão através da própria língua. Em relação ao estilo do poeta francês, Françoise Mélonio, Bertrand Marchal e Jacques Noiray, em La littérature française, acrescentam:

Mallarmé fez finalmente a descoberta do nada, que determina uma crise de vários anos, uma conversão do idealismo absoluto ao materialismo ateu, e uma consciência nova da poesia que não é mais uma via de acesso ao absoluto mas, como Deus, uma "Gloriosa Mentira".

Junto ao poeta da "crise de vers", muitos outros poderiam ser citados para compor o quadro dos denominados modernos, ou dos que serviram à constituição dessa "consciência nova da poesia". Muitos contribuíram para a atmosfera de destruição da missão social do poeta engajado, tal como preconizavam os românticos, e da qual Victor Hugo foi a figura mais representativa. Aliás, considerando essa crise anunciada contra a poesia, parece-me que a palavra 'maldito' com que Paul Verlaine ${ }^{5}$ designa um certo conjunto de poetas não foi empregada por acaso; com essa atitude, ele subverte a lógica do sagrado encontrada em Victor Hugo e ironizada por Baudelaire. Benoit Denis, em Littérature et engagement, define esse sagrado da poesia romântica como um "messianismo poético", em que o poeta figuraria como guia espiritual e moral, e, portanto, imbuído também do dever de ser um manejador do jogo político.

No entanto, é preciso lembrar que essa sensibilidade forjada na era romântica difere radicalmente da moderna, posto que desde Rimbaud e os autores modernos a figura do poeta ganha e perde seus contornos em meio às crises que dramatiza com a desconfiança em relação ao 'eu' ("Je est un autre") e à constatação cada vez mais disseminada de que a linguagem escapa e esconde ao mesmo tempo em que (se) revela em meio aos processos do inconsciente.

Tudo o que dissemos nos permite avançar essa discussão no seguinte sentido: se, por um lado, a época moderna não se conforma às representações de um poeta a quem o povo deve escutar e seguir, nem à moral cristã encrustada no pensamento romântico, por outro, ela se vê diante da necessidade de reinventar novas raz̃oes de ser, que expressariam, sobretudo, seus novos modos de interferir na realidade. Assim, Francis Ponge, em "Des Raisons d'écrire", texto escrito entre 1929 e 1930 e publicado em Proêmes, de 1948, expõe aquelas que seriam suas razões de escrever:

Qu'on s'en persuade: il nous a bien fallu quelques raisons impérieuses pour devenir ou pour rester poètes. Notre premier mobile fut sans doute le dégoût de ce qu'on
4. MARCHAL, B; MÉLONIO, F \& NOIRAY, J. "Marginaux et Maudits", 2007, p. 424.

5. Trata-se do livro de Paul Verlaine, Les poètes mandits, publicado primeiramente em 1884, depois, em uma segunda versão ilustrada, em 1888. Cf. VERLAINE, Paul. Les poètes maudits, 2012.

6. DENIS, Benoit. Littérature et engagement: de Pascal à Sartre, 2000, p.185.

7. RIMBAUD, Arthur. Euvres, 1998, p. 313. 
8. PONGE, Francis. Euvres

Complètes I, 1999, p. 195.

9. DENIS, Benoit. Littérature et engagement: de Pascal à Sartre, 2000, p. 11.

10. RANCIÈRE, Jacques.

Políticas da escrita, 1995, p. 7-8. nous oblige à penser et à dire, de ce à quoi notre nature d'hommes nous force à prendre part. ${ }^{8}$

Esse fragmento parece subverter completamente o foco do pensamento romântico e mergulhar definitivamente nas questões que envolveram o século XX e os escritores modernos. As razões para escrever, motivadas pela revolta, pelo desgosto em relação ao mundo, distanciam-se em larga medida das almejadas pelos poetas da era anterior. Se a razão pongiana aparece sob a forma de um enfrentamento ("Qu'on s'en persuade"), isso ocorre na tentativa de protestar contra uma ordem social perversa que lhe causa repulsa, obrigando-o também a participar de sua lógica. A postura do poeta vai, então, no sentido de resistir a um certo modo de "penser" e de "dire". Modo esse que se encouraça na língua, que é, segundo Ponge, "notre nature d'hommes".

Para iniciar o debate em torno desses novos pressupostos, sugiro pensarmos sobre o modo como a poesia nesse momento se coloca em relação ao mundo; sobre seu papel social, e sobre como ela vislumbra o próprio exercício de escrita que a constitui. Sendo assim, é preciso tentar entender como, a despeito da perda dessa aura romântica do poeta como portador de uma verdade para o povo, o escritor moderno continua a produzir um tipo de intervenção na realidade que o cerca, já que, como vai lembrar Denis, tal perspectiva nunca esteve totalmente ausente:

Desde as reflexões de Platão, na República, sobre o lugar dos poetas na cidade, até a maneira através da qual o poder real organizou a edição e a censura no século XVIII, tudo indica que a literatura não foi nunca um objeto neutro e indiferente em termos políticos?.

As considerações de Denis, acrescentadas às de Ponge, levam-nos a intuir que a relação entre literatura e política se dá de maneira complexa. Segundo Jacques Rancière, em Políticas da escrita, "antes de ser um sistema de formas constitucionais ou de relações de poder, uma ordem política é uma certa divisão das ocupações [...] em uma relação entre os modos do fažer, os modos do ser e do dizer" ${ }^{210}$ que se constituem no cerne de uma comunidade. Isso quer dizer que a política aqui ultrapassaria as instâncias formais, seu campo de atuação indo muito além das lutas ideológicas e das manifestações públicas.

A partir de tal perspectiva, Rancière denuncia uma visão simplista do engajamento da literatura. Em termos gerais, aquela que considera como intervenção política somente a escrita que se coloca em defesa de um determinado campo político-ideológico, pensando o autor engajado como aquele que pretende com a sua produção literária servir a um certo ideal de 
modo explícito. O engajamento da literatura é, para Rancière, mais complexo e menos manipulável do que se pensa. É o que o filósofo demonstra, em Politiques de la littérature, ao dizer que "os escritores lidam com os significados. Eles utilizam as palavras como instrumentos de comunicação e se encontram nesse sentido engajados, quer queiram, quer não, nas tarefas da construção de um mundo comum"11.

Com essas palavras, Rancière defende que, ainda que o autor não se coloque no debate público, pessoalmente, a sua obra tem impactos imprevisíveis na percepção do leitor, e por consequência, no agenciamento do real. A escrita seria, então, em suas variadas formas, um mecanismo regulador dos modos de "fazer", "ser" e "dizer" das e nas sociedades.

Ainda de acordo com Rancière, agora em Le partage du sensible, a literatura e a política propriamente dita não podem ser tão facilmente dissociadas, isso porque tanto uma quanto outra interferem no modo como os indivíduos sentem e realizam as ações cotidianas. Ambas estariam construindo "ficções" e contribuiriam espontaneamente para a constituição de uma sensibilidade comum, ou seja, de uma subjetividade compartilhada por um determinado grupo social. Rancière chama esse fenômeno de "regimes de intensidade sensível":

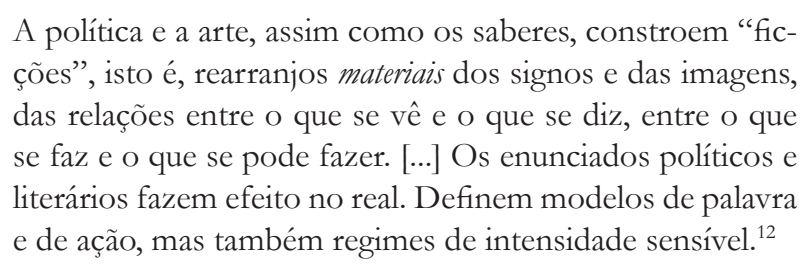

Assim, enquanto forma de expressão artística, a poesia também constitui um saber e por isso mobiliza modos de olhar e de dizer, instaurando novos "mapas do visível", ou seja, espécies de recortes do real que influenciam e até determinam atitudes, "modificam as maneiras, as velocidades e os trajetos segundo os quais os humanos aderem a uma condição, reagem a situações, reconhecem suas imagens" ${ }^{\prime 13}$. Articulando as palavras de Rancière com as raz̃oes pongianas, podemos perceber que os mecanismos linguísticos, vistos como peças reorganizadoras dos sistemas estabelecidos, situam-se, para o filósofo e para o poeta, no centro de suas perspectivas. Esse aspecto em Ponge é uma de suas características mais modernas, pois o trabalho com a língua como modo de intervir no mundo constitui uma das maiores encenações da poesia desde Mallarmé. Consideremos, nesse sentido, outro trecho de "Des Raisons d'écrire", em que, mais uma vez, o poeta expressa sua "rage" por uma sociedade que vive e produz significantes "sordide[s]":
11. Idem. Politiques de la littérature, 2007, p. 13.

12. Idem. Le partage du sensible. Esthétique et politique, 2000, p. 62.

13. Ibidem, p. 62. 
14. PONGE, Francis. Euvres Complètes I, 1999, p. 196.

15. GLEIZE, Jean-Marie. Francis Ponge, 1988, p. 49.

16. Ponge sentiu de perto essas atrocidades. Beugnot conta que ele teve que lidar, no início da guerra, com a morte em batalha de um familiar próximo: "Alfred Saurel, irmão caçula de Juliette Saurel [mère de Ponge], que se comportava mais como (tendo em vista sua idade) um primo que como um tio de Francis, morre nos primeiros dias da guerra em 1915”. Cf. Bernard Beugnot, apud. PONGE, Francis. Euvres Complètes II, 2002, p. XVI.
Honteux de l'arrangement tel qu'il est des choses, honteux de tous ces grossiers camions qui passent en nous, de ces usines, manufactures, magasins, théâtres, monuments publics qui constituent bien plus que le décor de notre vie, honteux de cette agitation sordide des hommes non seulement autour de nous, nous avons observé que la Nature autrement puissante que les hommes fait dix fois moins de bruit, et que la nature dans l'homme, je veux dire la raison, n'en fait pas du tout. ${ }^{14}$

Logo na primeira leitura, essas palavras nos chegam como um panfleto violento em que o "bruit", a "agitation", advindos da intensificação da ordem capitalista que silencia a "nature dans l'homme", sua "raison", são atacados. Ponge denuncia esse estrondo das máquinas, "grossiers camions" que não produzem sentidos senão através de ruídos ensurdecedores (e silenciadores) que ecoam "en nous". O contexto desse poema não poderia ser mais significativo de uma fase eruptiva da escrita de Ponge. Por volta de 1929 ou 1930, o poeta, como assinala Jean-Marie Gleize, em Francis Ponge, "assume” um "pertencimento" "subjetivo, reivindicado"15 em relação ao surrealismo, compartilhando, de certa forma, os mesmos impulsos negativos daqueles jovens.

$\mathrm{Na}$ verdade, desde a chegada da Primeira Guerra, em 1914, a literatura encontrou sua expressão mais exata na revolta contra as atrocidades protagonizadas pelos conflitos da guerra ${ }^{16} \cdot \mathrm{Na}$ era das vanguardas europeias, a poesia, na esteira da crise anunciada pelos modernos, tornou-se um instrumento através do qual jovens escritores expunham suas revoltas. Nesse sentido, os movimentos literários adicionaram à escrita um sentimento de repugnância não somente em relação à máquina política, mas sobretudo contra a própria sociedade, cujos valores eles consideravam como modo de perpetuação da injustiça e da guerra. O niilismo de Tristan Tzara, mentor do dadaísmo, e as intervenções extravagantes do grupo exemplificam bem o desejo desses artistas de intervirem nos sistemas constituídos.

Nessa tentativa radical dos vanguardistas de instaurar a revolta, a representação do poeta não ficou intacta, pelo contrário, ela foi também um alvo de investida, transformou-se em um objeto passível de ser atacado. Havia na atitude desses artistas uma tendência a desmantelar a imagem do poeta, entranhada na cultura francesa desde a forte presença de Victor Hugo, que, como mencionado anteriormente, fez da poesia uma tribuna de onde poderia professar as suas causas e ser ouvido como uma voz legitimada.

Essas características dos poetas surrealistas nos permitiriam situá-los, então, entre os modernos, que, como reiteramos, se dedicavam a uma linguagem experimental cujo sentido se veria subjugado à própria "forma" do fazer poético, ao mesmo 
tempo em que, contraditoriamente, resgatam valores que os aproximariam da era hugoana e da pretensão romântica de redenção dos valores de toda uma geração.

Diante desse cenário surrealista, Francis Ponge parece trabalhar no sentido de estruturar suas próprias "razões de escrever". Mesmo tendo sido apresentado a alguns poetas surrealistas na década de 1920, Ponge veio a se tornar conhecido do grande público somente em 1942, após a publicação de Le Parti pris des choses. Mas, diferentemente de muitos poetas da época, o escritor não parecia acreditar em uma junção harmônica entre os modi operandi $\mathrm{da}$ arte e as ideologias propagadas pelos partidos políticos da época. Antoine Compagnon, em La littérature française: dynamimique \& histoire II, chega a afirmar que ele "zomba [...] de toda poesia que acredita mudar a ordem das coisas" $"$. No entanto, vimos há pouco que havia em Ponge o mesmo sentimento que movia o surrealismo: a raiva contra a sociedade e contra a literatura: "Cela, c'est très nouveau pour moi, ce sentiment de révolte vis-à-vis de la société. En même temps que cela, naît ma révolte contre la littérature qui exprime cette sociéte" ${ }^{18}$. Em entrevista a Philippe Sollers, Ponge descreve o seu encontro com Breton da seguinte forma:

Ce nom [André Breton] est arrivé sur moi, tout simplement comme une information. A ce moment-là [...] il m'a semblé qu'évidemment Breton et ses amis n'étaient pas si différents de moi. [...] ils [1']étaient beaucoup, quant à leur comportement, mais ils [l] ${ }^{2}$ taient beaucoup moins quant aux problèmes qu'ils se posaient. ${ }^{19}$

Breton, seus amigos e Ponge viviam em um contexto de guerra, foram igualmente atravessados pelas questões que levaram a uma revolução na Rússia e a rebeliões em toda a Europa, e estavam diante de uma sociedade que, para eles, encarnava a hipocrisia moral de uma burguesia que os repelia. A produção literária desses jovens era, sem sombra de dúvida, marcada por um contexto politicamente conturbado. Assim, como explica Michel Collot, em Francis Ponge, entre mots et choses, a identificação de Ponge com o grupo surrealista se deu mais por vias políticas que literárias, visto que as práticas deste se afastavam da concepção literária vislumbrada pelo poeta: "[a] exigência de rigor, [a] preocupação com o real distancia Ponge, no plano literário, dos surrealistas, com quem ele compartilha somente o combate político. E mesmo nesse aspecto, ele se distanciará rapidamente" ${ }^{20}$.

Como mostra Collot, o método pongiano se afasta das práticas empreendidas pelo grupo vanguardista: para o poeta, não seria através de uma ação extravagante que ele deveria expressar sua revolta, nem por meio de uma poesia que se dedicasse inteiramente a instigar à ação. Ele explica, assim, por que a adesão
17. COMPAGNON, Antoine. La littérature française : dynamique \& histoire II, 2007, p. 726.

18. PONGE, Francis. Entretiens de Francis Ponge avec Philippe Sollers, 1970, p. 51.

19. Ibidem, p. 56-57.

20. COLLOT, Michel. Francis Ponge: entre les mots et les choses, 1991, p. 55-56. 
21. PONGE, Francis. Entretiens de Francis Ponge avec Philippe Sollers, 1970 , p. 61.

\section{COMPAGNON, Antoine.}

La littérature française: dynamimique \& histoire II, 2007, p. 726.

23. PONGE, Francis. Entretiens de Francis Ponge avec Philippe Sollers, 1970 , p. 61.

24. COMPAGNON, Antoine. La littérature française: dynamimique \& histoire II, 2007, p. 726.

25. PONGE, Francis. Entretiens de Francis Ponge avec Philippe Sollers 1970 , p. 61.

26. BRETON, André.

"Manifeste du surréalisme". Euvres Complètes I, 1988, p. 327.

27. GLEIZE, Jean-Marie. Francis Ponge, 1988, p. 59. ao grupo de Breton não poderia, nesse momento, apesar das afinidades, se dar: "je me retirais du surréalisme, c'est-à-dire que je n'y adhérais pas et que si les questions qu'il posait m'intéressaient, j'étais tout à fait contre ses attitudes spectaculaires" 21 .

Nessa perspectiva, Compagnon chama atenção para o fato de que o escritor "não havia se sacrificado à poesia utilitária e aplicada" 22 . A postura de Ponge em relação às "attitudes spétaculaires" 23 surrealistas leva o crítico a concluir que o poeta renega a intervenção panfletária via literatura: "Recusando-se a submeter o risco poético a uma profissão de fé ou a um programa social, ele havia defendido que o poeta que confunde a poesia com a ação renuncia à poesia" 24 . Podemos, assim, evidenciar a posição crítica do autor de Le Parti pris des choses em relação a essa submissão do artista às ideologias políticas. Seria, afinal, o que ele censura nos surrealistas: a pretensão de trabalhar a favor de uma transformação do mundo não apenas através das palavras, mas atuando diretamente na esfera política.

Évidemment, ce qui est absurde, en quelque façon, chez les surréalistes, c'est de croire qu'ils faisaient autre chose que de la littérature. Finalement, tout ça est maintenant dans l'histoire littéraire et tout s'est classé dans les bibliothèques françaises. Eh bien, moi, j'en ai été toujours conscient ; j'ai toujours été assez positif, assez matérialiste, enfin, pour me rendre compte de cela. ${ }^{25}$

De fato, o surrealismo pretendia não apenas interferir nas normas que regulamentavam a literatura e a arte, mas também pôr em questão todas as manifestações dessa civilização que lhe parecia tão permissiva às guerras. No primeiro manifesto, Breton define os propósitos do movimento da seguinte forma: "Il tend à ruiner définitivement tous les autres mécanismes psychiques et à se substituer à eux dans la résolution de principaux problèmes de la vie"26. No contexto histórico em que Ponge estava inserido, como se sabe, as provocações em vista de uma revolução e a reação muito virulenta e negativa em relação à política eram habituais e mobilizavam um grande número de artistas e escritores.

Certamente Ponge não quis, em um primeiro momento, inscrever seu nome entre os escritores que trabalhavam a favor do partido comunista e das ideologias políticas da época, como mostrou Compagnon. No entanto, Gleize lembra que, nos anos 1920, Ponge, "antes do que ele chama de sua proletarização, e sua politização 'concreta', era bem mais anarquista e anarquizante que marxista" 27 . Uma característica que, apesar de estar na contramão do surrealismo e dos grupos revolucionários, era bem representativa de um sentimento de contestação em relação ao mundo e à política, portanto, mas que não se rendia a nenhuma organização ideológica: "Francis Ponge nunca apreciou 
qualquer adesão que fosse a alguma das variantes da ideologia anarquista" ${ }^{28}$.

A resposta de Ponge a essas tendências literárias da época foi dada no intuito de fundar uma modernidade que indicasse outro caminho para o homem. Nesse sentido, sua obra pode ser pensada como uma chave que amplia a discussão, pois traz à cena a relação entre o homem e as coisas e reabre a questão do papel do poeta na sociedade na medida em que pretende interferir no que há de mais humano, manipulando-o: a linguagem. Esta é, para ele, fonte de vida e esperança.

As razões pongianas para recorrer à escrita, assim como as dos surrealistas, se inscrevem em uma tentativa de denunciar uma realidade social injusta. Mas diferentemente destes, o poeta entrevê nessa atividade a possibilidade de remediar o dano causado às palavras pela "parole", termo que o poeta usa para se referir à fala comum, uma referência à oralidade. Os "camions" que entulham a cidade não apenas importunam por seu barulho excessivo, mas, ao representarem uma lógica social injusta de exploração do trabalho e repressão à criatividade do ser humano, também nos impõem seus significados sórdidos. Essa ordem, ao manifestar-se nas instâncias da fala, dá a Ponge a dimensão do fracasso da língua, reduzida à função de informação - a "universal reportagem", de que falava Mallarmé. Mas o que está em jogo aqui não é a defesa de uma língua pura. A preocupação pongiana é a de ir contra o uso esterilizante dela, que coloca os indivíduos sob a ameaça do silêncio, forçado, obviamente, e do balbucio que não produz novos sentidos ${ }^{29}$, mas apenas reproduz os mesmos. Voltemos, então, por um instante às "razões de escrever" de Ponge:

N'en déplaise aux paroles elles-mêmes, étant donné les habitudes que dans tant de bouches infectes elles ont contractées. (...)

Qu'il faut à chaque instant se seconer de la suie des paroles et que le silence est aussi dangereux dans cet ordre de valeurs que possible.

Une seule issue : parler contre les paroles. Les entraîner avec soi dans la honte où elles nous conduisent de telle sorte qu'elles défigurent. Il n'y a point d'autres raisons d'écrire. ${ }^{30}$

Se toda essa sujeira ("la suie des paroles") pode resultar em um silêncio igualmente "dangereux", o combate do poeta está colocado: trata-se de investir contra a tendência dessas "paroles" de calá-lo. Escrever, dizer à revelia, resistindo a todos os limites instaurados pela lógica da utilidade a que a própria literatura parece estar subordinada, não somente lhe chega como seu método para superar o estado social e político das coisas, mas como única arma para escapar a uma submissão vergonhosa: a submissão ao silêncio.
28. Ibidem, p. 59.

29. Marcelo Jacques de Moraes assinala justamente como Ponge ao escrever/descrever um objeto pretende fazê-lo aparecer na e "para a língua", instaurando sentidos para o "bem" "dos seus leitores", como um "bem próximo". MORAES, M. J. "Pode-se comer um figo de palavras? Uma questão (antropofágica?) com/a Francis Ponge", 2016, p.42.

30. PONGE, Francis. CEures Complètes I, 1999, p. 196-197. 
31. Idem. CEuvres Complètes II, 2002, p. 154.

32. PONGE, Francis. Euvres Complètes I, 1999 , p. 654.

33. Ibidem, p. 654.

34. COLLOT, Michel. Francis Ponge: entre les mots et les choses, 1991, p. 57.

35. MATTONI, Silvio. "Retorno ao rascunho. Anotações sobre Ponge", 2016, p.33.
Daí à exaltação da escrita. Ponge chega por intermédio de um par magnífico: raison/ réson, à ideia de que escrever é se redimir, é fazer ressurgir na e pela palavra a contravenção do poeta, criando, reestabelecendo ressonâncias (réson), que o mundo viciado em seus sentidos não pode conceber, não pode sequer ouvir. Eis, nas palavras de Ponge, de seu Pour un Malherbe, de 1964, a raison da poesia: "opérer la confusion de la raison et de la réson. Ou si l'on veut, du raisonnement et du résonnement" 31 . Por isso, a decisão pela escrita, como o poeta explica em "Tentative orale", texto escrito, sobretudo, em 1947:

J'ai longtemps pensé que si j'avais décidé d'écrire, c'était
justement contre la parole orale, contre les bêtises que
je venais de dire dans une conversation, contre les
insuffisances d'expression au cours d'une conversation
même un peu poussée. ${ }^{32}$

Apesar dessa preferência declarada de Ponge em relação à escrita, esta não se realiza sem que se note certa ambiguidade. Longe de enaltecer por completo a escrita, o poeta parece expô-la em termos mais complexos; escrever pode ser um modo de colocar as coisas às claras ou uma estratégia "pour parvenir à une expression plus ambiguë". Ou seja, trata-se muito mais de se lançar em direção à escrita poética como quem se dirige a um objeto opaco, um "oraculaire" 33 , do que de crer em uma possibilidade de exatidão advinda dela.

Collot, refletindo sobre esse ponto da poética pongiana, acrescenta mais um elemento importante. Ele assinala que "o fato de consagrar um poema a um objeto tão prosaico e desvalorizado se reverte em uma significação polêmica e evidente". Desse modo, "conferir dignidade poética às coisas triviais é revirar a hierarquia instituída pela ordem social" ${ }^{34}$. Dar voz às coisas mudas seria de certa forma uma medida compensatória, já que, fazendo isso, o poeta acabaria por preencher o mundo com outros sentidos negligenciados pelo uso repetitivo da língua. Nessa atitude de Ponge, que é também seu parti pris da língua, há também o desejo de confrontar a coisa à sua inscrição muda na história da língua francesa. Trata-se de escrever sobre o seixo, o caixote, o sabão, a fim de explorar o contato entre duas realidades, a física e a verbal, reestabelecendo a vivacidade desse encontro através da escrita. Silvio Mattoni, em "Retorno ao rascunho. Anotações sobre Ponge", assinala o entendimento pongiano em se aproximar das coisas:

Tomar o partido das coisas não seria, então, simplesmente entender essas coisas como objeto da poesia, como um estilo, mas tentar dar a cada coisa sua maneira de calar na linguagem: não um estilo do poeta, declarará Ponge, mas um estilo para cada objeto. ${ }^{35}$ 
Desse modo, em Le Parti pris des choses, seu maior empreendimento consiste em ir às coisas e nos fazer ver nelas uma dimensão material inusitada, ao estilo do próprio objeto, e independente do significado social mais comum. O "papillon", por exemplo, é uma "allumette volante", mas cuja chama " $n$ 'est pas contagieuse". Os "escargots", diferentemente das "escarbilles", amam a "terre bumide". E "la cigarette", com sua fumaça "parfumée", determina a cada vez "un nombre calculable de petites masses de cendres" ${ }^{36}$.

O que Ponge parece pretender denunciar com o seu método é a concepção ingenuamente aceita pelo senso comum de que a língua é um simples instrumento a serviço do pensamento. Nesse sentido, é possível entrever em seu discurso um desejo em ir de encontro à ideia de que o homem manipula a linguagem a seu modo e que a interferência política e social se faz apenas ou, sobretudo, através de uma escrita que se pretende a serviço de um dado questionamento político e/ou social.

\section{Referências}

BRETON, André. "Manifeste du surréalisme". In:

Euvres Complètes I. Paris: Gallimard, 1988.

COLLOT, Michel. Francis Ponge: entre les mots et les choses. Col. Champ Poétique Mayenne: Champ Vallon, 1991.

COMPAGNON, Antoine. La littérature française: dynamique \& histoire II. Paris: Gallimard, 2007.

DENIS, Benoit. Littérature et engagement: de Pascal à Sartre. Paris: Seuil, 2000.

GLEIZE, Jean-Marie. Francis Ponge. Paris: Seuil, 1988.

MALLARMÉ, Stéphane. CEuvres Complètes II. Bibliothèque de la Pléiade. Paris: Gallimard, 2003.

MAULPOIX, Jean-Michel. Du Lyrisme. Paris: José Corti, 2000.

MARCHAL, B; MÉLONIO, F \& NOIRAY, J. "Marginaux et Maudits" In. DELON et al. La littérature Française : dynamique et histoire II. Paris: Gallimard, 2007.

MATTONI, Silvio. "Retorno ao rascunho. Anotações sobre Ponge”. Tradução Byron Vélez Escallon. In. SCRAMIM, S; SISCAR, M \& PUCHEU, A. (org.) Linhas de fuga: Poesia, modernidade e contemporaneidade. São Paulo: Iluminuras, 2016.
36. PONGE, Francis. Euvres Complètes I, 1999, p. 19-29. 
MORAES, M. J. "Pode-se comer um figo de palavras? Uma questão (antropofágica?) com/a Francis Ponge". In. SCRAMIM, S; SISCAR, M \& PUCHEU, A. (org.) Linhas de fuga: Poesia, modernidades e contemporaneidade. São Paulo: Iluminuras, 2016.

PONGE, Francis. CEuvres Complètes I. Bibliothèque de la Pléiade, Paris: Gallimard, 1999.

Euvres Complètes II. Bibliothèque de la Pléiade, Paris: Gallimard, 2002.

Entretiens de Francis Ponge avec Philippe Sollers. Paris: Gallimard/Seuil, 1970.

RANCIÈRE, Jacques. Políticas da escrita. Tradução Raquel Ramalhete, Laís Eleonora Vilanova, Lígia Vassalo e Eloísa Araújo Ribeiro. Rio de Janeiro: Editora 34, 1995. . Politiques de la littérature. Paris: Galilée, 2007. . Le partage du sensible. Esthétique et politique. Paris: La Fabrique, 2000.

RIMBAUD, Arthur. EEwres. Paris: Pocket, 1998.

VERLAINE, Paul. Les poètes mandits. Paris: Hachette, 2012. 